\title{
Dynamic Monitoring of Cellular Remodeling Induced by the Transforming Growth Factor- $\beta 1$
}

\section{Andrea Staršíchová, Lukáš Kubala, Eva Lincová, Zuzana Pernicová, Alois Kozubík, and Karel Souček}

\begin{abstract}
The plasticity of differentiated adult cells could have a great therapeutic potential, but at the same time, it is characteristic of progression of serious pathological states such as cancer and fibrosis. In this study, we report on the application of a real-time noninvasive system for dynamic monitoring of cellular plasticity. Analysis of the cell impedance profile recorded as cell index using a real-time cell analyzer revealed its significant increase after the treatment of prostate epithelial cells with the transforming growth factor- $\beta 1$. Changes in the cell index profile were paralleled with cytoskeleton rebuilding and induction of epithelial-mesenchymal transition and negatively correlated with cell proliferation. This novel application of such approach demonstrated a great potential of the impedance-based system for noninvasive and real-time monitoring of cellular fate.
\end{abstract}

Key words: real-time cell analysis, cell plasticity, epithelial-mesenchymal transition, transforming growth factor- $\beta 1, \mathrm{~F}$-actin, cytoskeleton remodeling.

\section{Introduction}

The phenomenon of plasticity of differentiated adult cells could have a great therapeutic potential, but at the same time, it is characteristic of progression of serious pathological states. Epithelial-mesenchymal transition (EMT) is a crucial process in embryogenesis, but it also occurs during progression of tumors derived from epithelial cells (for review, see $(1)$ ). The transforming growth factor- $\beta \mathrm{l}$ (TGF- $\beta \mathrm{l}$ ) is an important growth factor inducing remodeling of epithelial cells. TGF- $\beta 1$ induces a complex change of the gene expression profile, which leads to the induction of cell cycle arrest, increased cell

Shulin Li (ed.), Biological Procedures Online, Volume 11, Number 1

(C) to the author(s) 2009

DOI: 10.1007/s12575-009-9017-9 URL: springerprotocols.com; springerlink.com 
migration, and spreading (2-4). In general, determination of the quality and quantity of remodeling of epithelial cells is a complex issue. It usually includes quantification of expression of epithelial and mesenchymal markers (E-cadherin, $\mathrm{N}$-cadherin, and vimentin), visualization of cytoskeletal rebuilding (F-actin), migration, and invasive assay (wound healing and migration through Matrigel matrix; (5)). Conventionally, most of the approaches mentioned are based on a time-consuming end-point analysis of the state of whole cell populations combined with advanced techniques of analysis of individual cells with the use of flow cytometry or digital microscopic techniques and image analysis. However, neither the episodic nor the spatial resolution of these techniques is capable of registering very small and fast changes in cellular morphology. Currently, label-free and noninvasive methods based on electronic cell sensor arrays were suggested for the monitoring of cell physiology, particularly adhesion, spreading, and transient changes in cell morphology (6-9). To widely accept this methodological approach and to correctly and precisely interpret data for these measurements is crucial to obtain precise correlation with cell morphology and overall phenotype using a relevant reference method. However, well-described models applying this methodological approach with different cell lines and various cell plasticity modulating conditions are missing. Here, we showed that the impedance-based real-time cell analyzer (RTCA) allows dynamic monitoring and quantification of cell remodeling during TGF- $\beta 1$-induced EMT in non-transformed prostate epithelial cells. This novel application of such approach demonstrated a great medium-throughput potential of the impedance-based system for noninvasive and real-time monitoring of cellular fate.

\section{Materials and methods}

\subsection{Cells}

2.2. Real-time cell impedance analysis
BPH-l cells were obtained from the German Collection of Microorganisms and Cell Cultures and cultivated in RPMI 1640, supplemented with $20 \%$ bovine fetal serum (both PAA), $5 \mu \mathrm{g} / \mathrm{ml}$ transferrin, $5 \mathrm{ng} / \mathrm{ml}$ sodium selenite, and $5 \mu \mathrm{g} / \mathrm{ml}$ insulin (Invitrogen). The cell lines were cultivated in Nunc (Thermo Fisher Scientific) cultivation dishes, flasks, and plates in a humidified incubator at $37^{\circ} \mathrm{C}$ in an atmosphere of $5 \% \mathrm{CO}_{2}$.

Acea E-plates ${ }^{\circledR} 96$ were used for noninvasive real-time measurement with the use of an xCELLigence RTCA SP system including RTCA Software version 1.1 (both Roche). First, a standard background measurement was performed using $100 \mu \mathrm{l}$ of complete cultivation media. BPH-1 cells were trypsinized, quantified, and seeded in 


\subsection{Cell counts}

2.4. ATP assay

2.5. Fluorescent and light microscopy

2.6. Western blot additional $100 \mathrm{ul}$ of cultivation media in a final concentration of 30,000 cells per $\mathrm{cm}^{2}$. The cells were monitored continually every $\mathrm{l} \mathrm{min}$ in the first $45 \mathrm{~min}$ after the seeding and then every $\mathrm{l} \mathrm{h}$ for a period of $96 \mathrm{~h}$. Recombinant TGF- $\beta \mathrm{l}$ (Millipore) treatment with various concentrations in triplicate was performed $24 \mathrm{~h}$ after the seeding of the cells. Formation of contractile microfilaments was blocked by cytochalasin B (CB), Helminthosporium dematioideum (Calbiochem) dissolved in methanol $(\mathrm{MeOH})$. The cells were pretreated with TGF- $\beta 1(10 \mathrm{ng} / \mathrm{ml})$ for $68 \mathrm{~h}$ and treated with $\mathrm{CB}$ $(10 \mu \mathrm{g} / \mathrm{ml})$ for another $3 \mathrm{~h}$. The cells were monitored continually every $15 \mathrm{~s}$ after the $\mathrm{CB}$ addition. In this case, data are presented as a normalized cell index (CI; normalized at the time of $68 \mathrm{~h}$ ). Cultivation of the cells and their treatment were performed under standard conditions $\left(37^{\circ} \mathrm{C} / 5 \% \mathrm{CO}_{2}\right)$.

The numbers of trypsinized BPH-1 cells in the culture were determined using a Coulter Counter® ZM (Beckman-Coulter).

Intracellular ATP was detected in BPH-l cells by the commercial ATP cellular kit (Biothema, Sweden). The cells were incubated according to the experimental procedure, the supernatant was removed, and the cells were lysed by the Somatic cell ATP releasing reagent (Sigma-Aldrich). Then, $50 \mu$ l of lysate was mixed with $20 \mu \mathrm{l}$ of ATP reagent containing D-luciferin, luciferase, and stabilizers. Intracellular ATP contents were determined using a microplate luminometer LM-01T (Immunotech).

F-actin was visualized after the staining of paraformaldehyde $(2 \%)$ fixed and permeabilized BPH-l cells with phalloidin-fluorescein isothiocyanate (Sigma-Aldrich) using a fluorescent microscope (Olympus IX-70, Fluoview II CCD camera). Nuclear counterstaining was performed by using 4',6-diamidine-2'-phenylindole dihydrochloride (DAPI; Fluka). Cell morphology was documented by phase contrast on the same microscope.

$\mathrm{BPH}-\mathrm{l}$ cells were treated by various concentrations of TGF- $\beta 1$ for different time intervals and harvested in radioimmunoprecipitation assay buffer $(50 \mathrm{mM}$ Tris- $\mathrm{HCl} \mathrm{pH} 7.4,1 \% \mathrm{NP}-40,0.25 \%$ sodium deoxycholate, $150 \mathrm{mM} \mathrm{NaCl}$, protease inhibitor cocktail, and phosphatase inhibitor cocktail set II (Merck)). Protein concentration was determined using detergent-compatible protein assay (Bio-Rad). The cell lysates were sonicated ( $5 \mathrm{~s}$, Sonifier ${ }^{\circledR}$ B-12, Branson Ultrasonics Corp), spun, and mixed with $3 \times$ sodium dodecyl sulfate (SDS) loading buffer ( $240 \mathrm{mM}$ Tris-HCl pH6.8, 6\% SDS, $0.02 \%$ bromphenol blue, $30 \%$ glycerol, $3 \% \beta$-mercaptoethanol). Equivalent quantities of protein $(20 \mu \mathrm{g})$ were separated by SDS-polyacrylamide gel electrophoresis and transferred onto polyvinylidene fluoride membranes (Millipore) using established procedures. The 
membranes were blocked in Tris-buffer saline $(20 \mathrm{mM}$ Tris- $\mathrm{HCl}$ pH7.2, $140 \mathrm{mM} \mathrm{NaCl}$ ) containing $0.1 \%$ Tween 20 and $5 \%$ nonfat milk. The levels of phosphorylated (Ser465/467) and total Smad2, and expression of vimentin, a characteristic mesenchymal marker, were analyzed with specific primary antibodies (Cell Signaling and Sigma-Aldrich). Anti- $\beta$-actin (A5441) was from Sigma-Aldrich; horseradish peroxidase-conjugated anti-mouse IgG (\#NA931) and anti-rabbit IgG (\#NA934) were from GE Healthcare. Detection of antibody reactivity was performed using Immobilon Western HRP Substrate (Millipore). Densitometric measurements were performed using ImageJ software (NIH) and normalized to the expression of $\beta$-actin.

\section{Results and discussion}

Data acquisition demonstrated a linear increasing of the CI values in control cells during the time interval observed. However, this linear trend was significantly changed by TGF- $\beta 1$ in less than $12 \mathrm{~h}$ after the treatment in a concentration-dependent manner (Fig. la). Concentrations of 1 and $10 \mathrm{ng} / \mathrm{ml}$ induced a significant steep increase in CI values, which reached a plateau in $48 \mathrm{~h}$. The impedance-based determination is by its nature dependent on the number of adherent cells. Thus, we compared CI determination with the analysis of cell numbers to clarify the contribution of changes in cell numbers and the morphological alternation of cells to detected CI values. In parallel with the E-plates ${ }^{\circledR} 96$, the cells were seeded at the same density on $40 \mathrm{~mm}$ dishes and 4-well plates, and treated with TGF- $\beta 1$ in the same experimental design. At various time intervals after the treatment, the numbers of trypsinized cells were determined using a Coulter Counter simultaneously with the determination of metabolically active viable cells based on determination of intracellular ATP in cell lysate. Our data, shown in Fig. 1b, c, demonstrate that TGF- $\beta 1$ induced antiproliferative effects in BPH-1 cells in a time- and concentration-dependent manner. These trends are in negative correlation with CI values acquired with the use of RTCA. Taken together, these data showed that the TGF- $\beta 1$ induced antiproliferative effects in $\mathrm{BPH}-1$ cells are paralleled by an increase of cell impedance.

It is a well-known fact that when stimulated with TGF- $\beta 1$, epithelial cells undergo EMT and exhibit a significant formation of actin stress fibers that emanate from focal adhesions (10). In this case, our results demonstrate the usual uncertainty of image analysis which is limited by confluence of the cells. The control cells reached a relatively high density after $72 \mathrm{~h}$ of cultivation. 

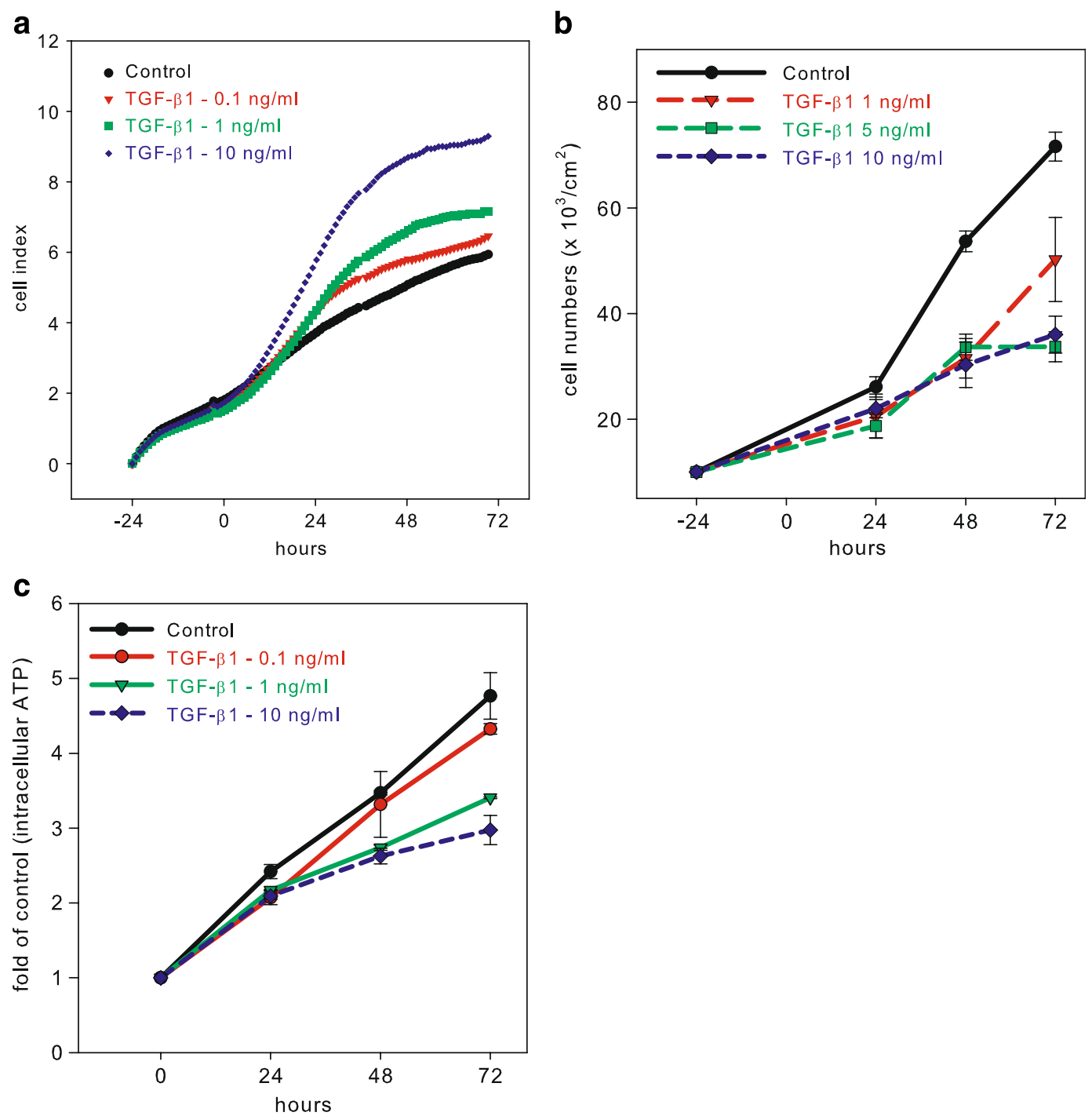

Fig. 1. The antiproliferative effect of transforming growth factor- $\beta 1$ (TGF- $\beta 1$ ) is associated with the increase of the cell index (impedance) in BPH-1 cells. a TGF- $\beta 1$ induces an increase of the cell index (impedance) acquired with the use of an XCELLigence real-time cell analyzer system in a time- and concentration-dependent manner. However, at the same time, TGF- $\beta 1$ strongly inhibits cell proliferation quantified by counting of the cells using a Coulter Counter (b), and by ATP assay (c). The cells were treated with various concentrations of TGF- $\beta 1$ at the time marked as time zero.

Based on the F-action visualization and cell morphology analysis, there is no significant difference between control cells and cells treated with $0.1 \mathrm{ng} / \mathrm{ml}$ of TGF- $\beta \mathrm{l}$. However, it is evident that TGF- $\beta \mathrm{l}$ at 1 and $10 \mathrm{ng} / \mathrm{ml}$ concentrations induced formation of F-actin stress fibers and increased cell spreading (Fig. 2). These results positively correlate with the activation of Smad-dependent signaling and EMT by TGF- $\beta$ I (Fig. 3). Our results showed transient phosphorylation of $S \operatorname{mad} 2$ induced by both 1 and $10 \mathrm{ng} / \mathrm{ml}$ of TGF- $\beta 1$, which is followed by massive induction of vimentin expression. TGF- $\beta 1$ at a 


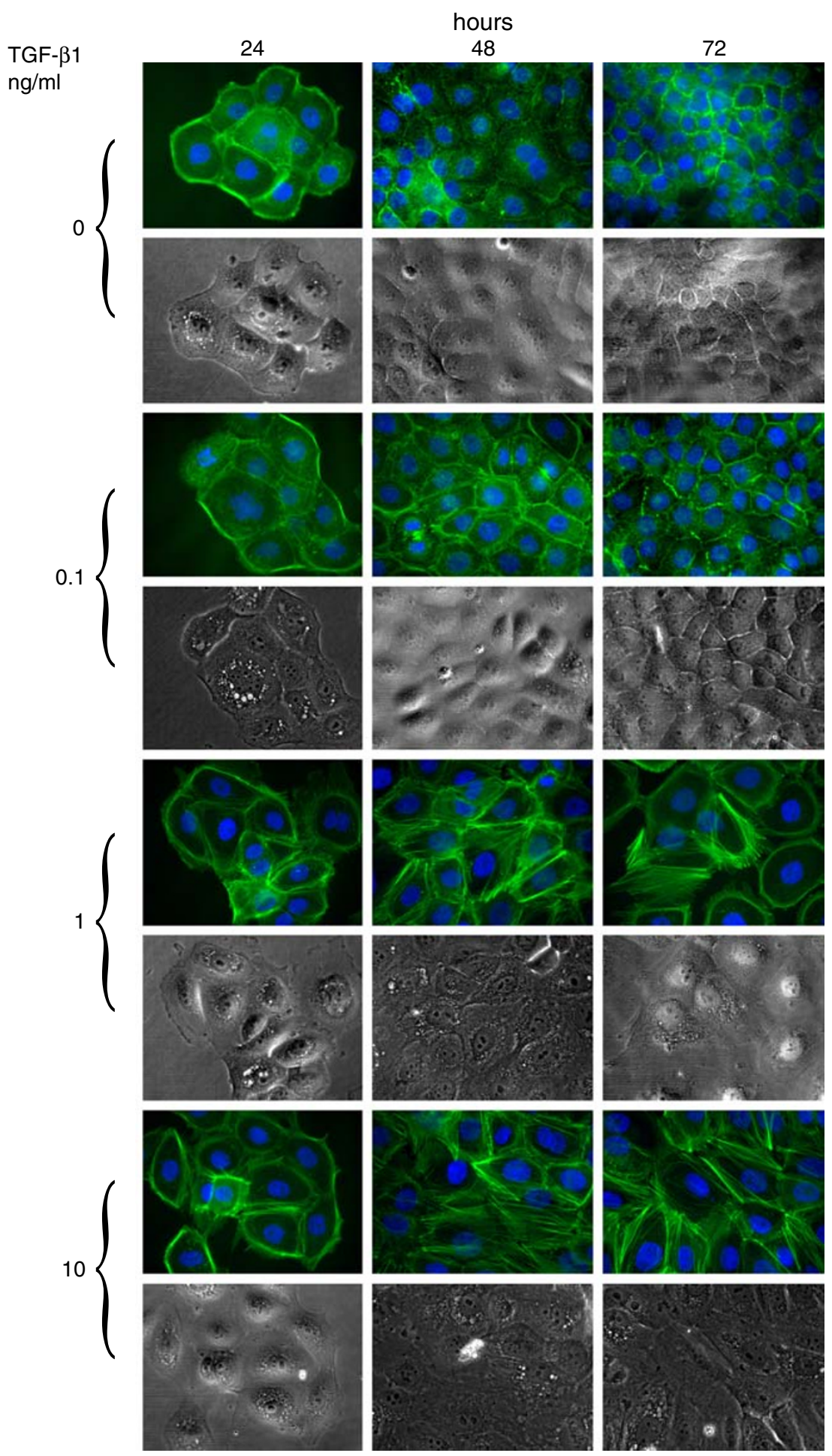

Fig. 2. The effect of transforming growth factor- $\beta 1$ in $\mathrm{BPH}-1$ cells is associated with remodeling of the cytoskeleton. F-actin was visualized with the use of phalloidin-fluorescein isothiocyanate conjugate. The nuclei were counterstained with DAPI. Images of cellular morphology were taken under phase contrast. 

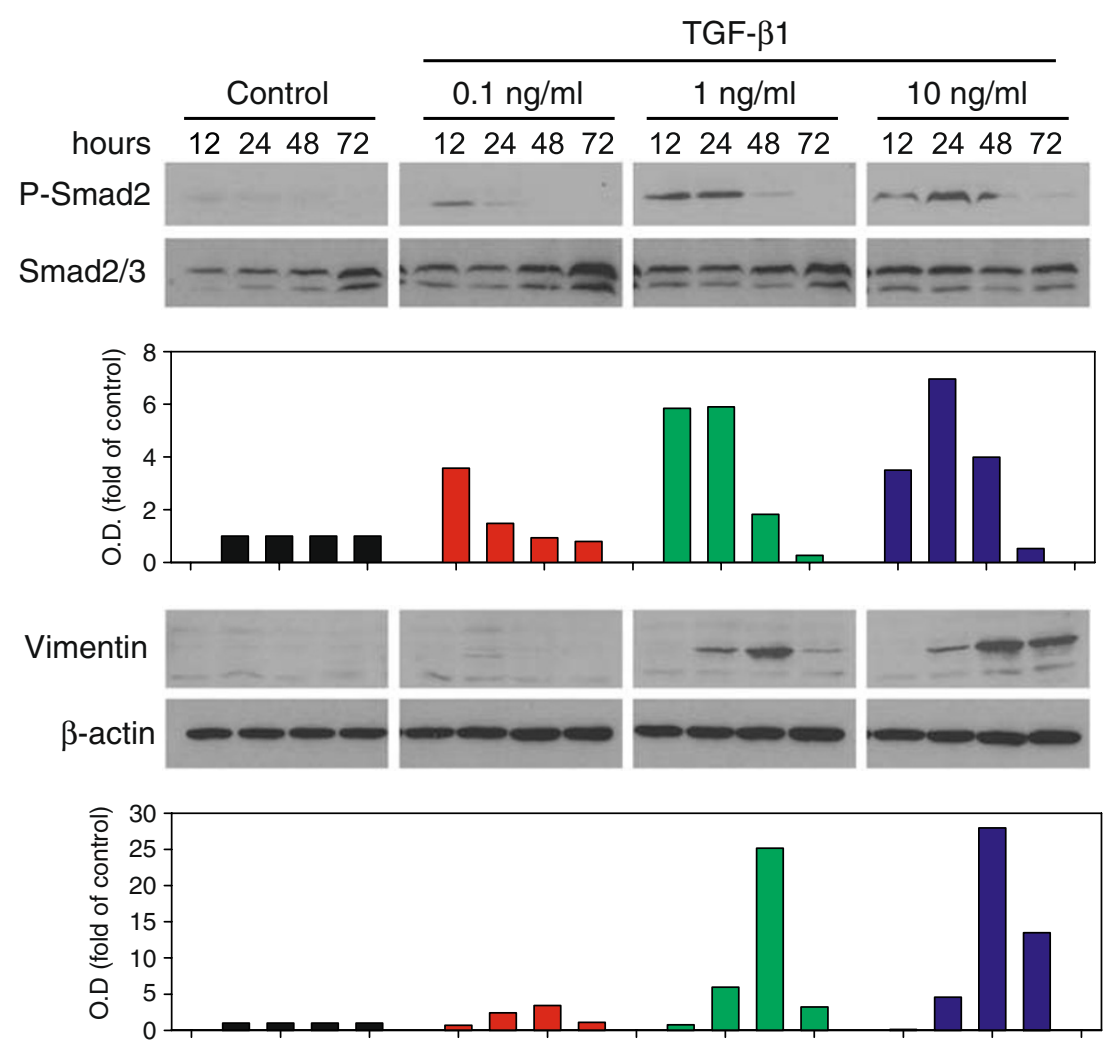

Fig. 3. Transforming growth factor- $\beta 1$ induces phosphorylation of Smad2 and epithelial-mesenchymal transition in $\mathrm{BPH}-1$ cells. The cells were lysed using radioimmunoprecipitation assay buffer, sodium dodecyl sulfate-polyacrylamide gel electrophoresis, and immunoblotting detection of $\mathrm{p}-\mathrm{Smad} 2$ (Ser465/467); Smad2 and vimentin was performed. Detection of $\beta$-actin served as control of equal loading. Densitometric measurements were performed using ImageJ software (NIH, Bethesda, MD, USA) and normalized to the expression of $\beta$-actin. The bar graph represents the average optical density.

concentration of $0.1 \mathrm{ng} / \mathrm{ml}$ did not induce vimentin expression and only slightly induced phosphorylation of Smad2. Furthermore, we wanted to examine the influence of formation of stress fibers on TGF- $\beta 1$-induced increase of $\mathrm{CI}$ values. $\mathrm{CB}$, a potent inhibitor of the formation of contractile microfilaments, induced inhibition of F-actin formation in both control and TGF- $\beta$ l-treated BPH-1 cells (Fig. 4a). This inhibition was paralleled by a rapid decrease of normalized CI values in both groups (Fig. 4b). However, the drop of CI values induced by $\mathrm{CB}$ was much stronger in the case of TGF- $\beta 1$-pretreated BPH-l cells, with high abundance of F-actin stress fibers in comparison with CB-treated control cells. These results demonstrate that TGF- $\beta 1$-induced increase of CI values is at least partially dependent on stress fiber formation. We can summarize that TGF- $\beta 1$-induced EMT in BPH-1 cells is associated with inhibition of proliferation, rebuilding of cytoskeleton, formation of stress fibers, and increase of spreading. These cellular changes are associated with a significant increase in CI values analyzed by the RTCA system. Until 
now, most of the applications of RTCA focused on analysis of adhesion or spreading were designed to study immediate interaction of cells with substrate in relatively short time intervals $(6,11)$. Here, our data suggest a novel application and a great potential of real-time impedance measurement for dynamic monitoring of cellular remodeling and plasticity, induced after adhesion of the cells to the substrate and formation of stress fibers in longer time intervals. Furthermore, these measurements also show a potential misinterpretation of the data in experimental setups using impedance-based methods for the detection of cell proliferation without simultaneous monitoring of cellular morphological changes.

a
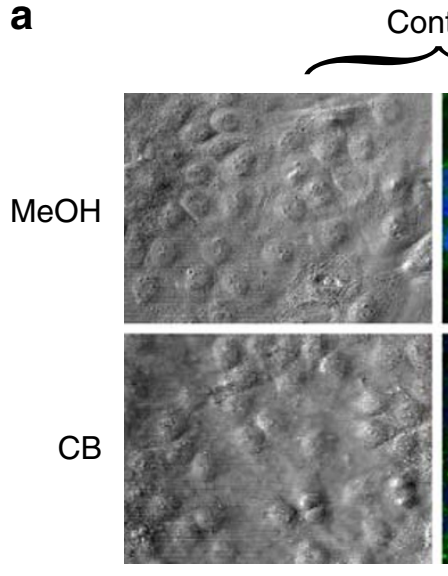

Control
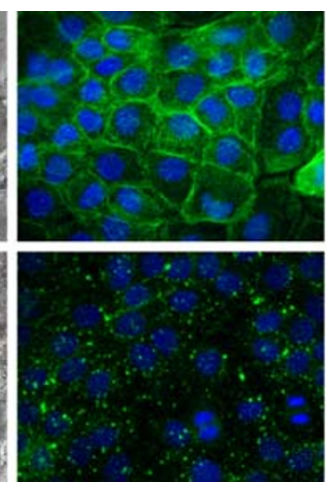
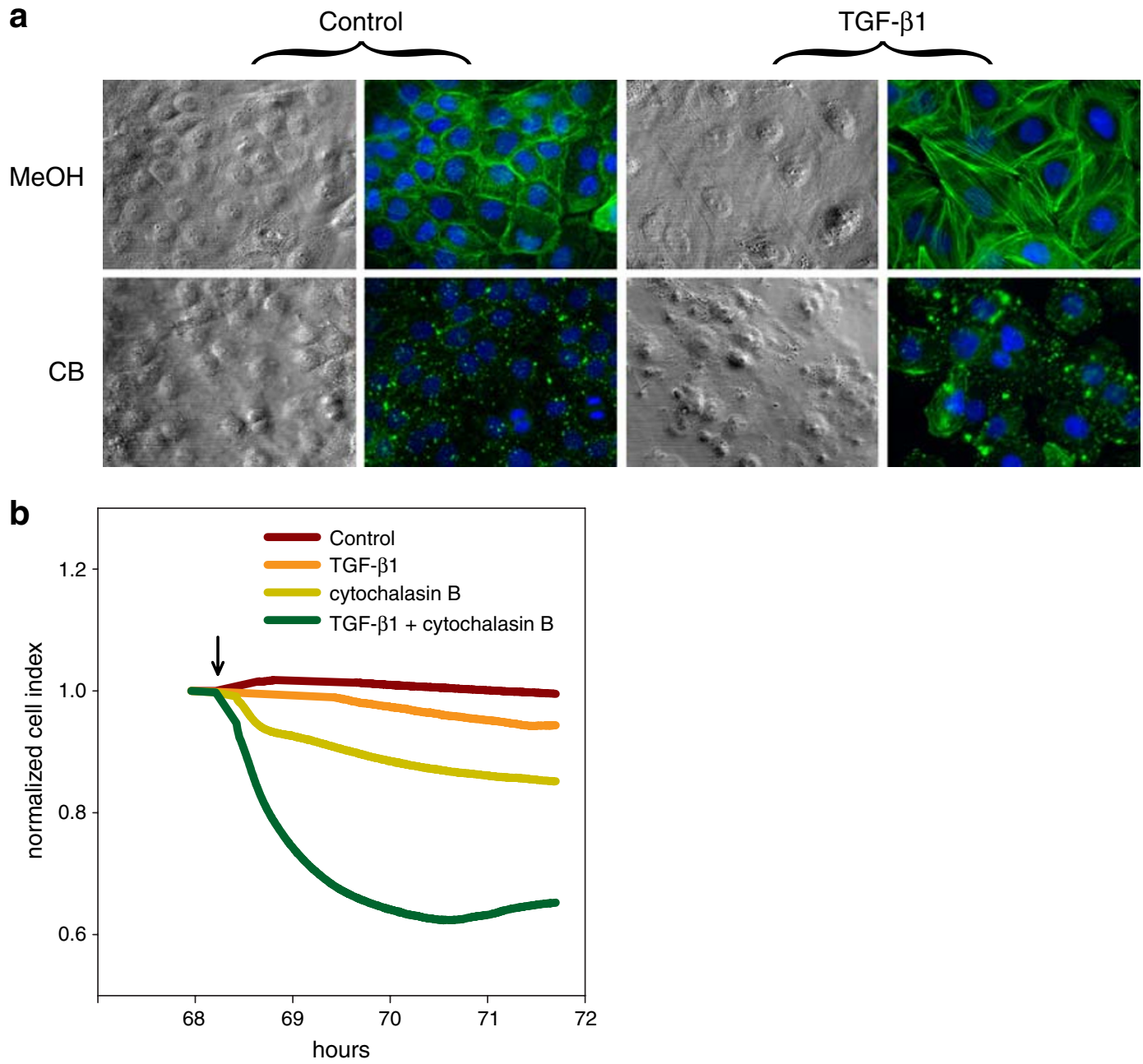

Fig. 4. Inhibition of formation of contractile microfilaments by cytochalasin B (CB) leads to a rapid drop of cell index values. BPH-1 cells were pretreated with transforming growth factor- $\beta 1(10 \mathrm{ng} / \mathrm{ml})$ for $68 \mathrm{~h}$ and treated with CB $(10 \mu \mathrm{g} / \mathrm{ml})$ for another $3 \mathrm{~h}$. a F-actin was visualized by phalloidin-fluorescein isothiocyanate conjugate after $3 \mathrm{~h}$ of $\mathrm{CB}$ and/or vehicle treatment. $\mathbf{b}$ CB induces a rapid decrease of the normalized cell index (data were normalized at the time of $68 \mathrm{~h}$ ) acquired with the use of an xCELLigence real-time cell analyzer system. The arrow indicates the time interval of CB addition. 
Acknowledgment

The authors would like to thank Viktor Horváth (Roche Czech Republic) for his assistance with xCELLigence RTCA, Iva Lišková, Jaromíra Netíková and Petra Jelínková for superb technical assistance, and Ladislav Červený for the correction of English. This work was supported by grant number 204/07/0834 of the Czech Science Foundation, and grants numbers AV0Z50040507 and AV0Z50040702 of the Academy of Sciences of the Czech Republic.

\section{References}

1. Kalluri R (2009) The basics of epithelialmesenchymal transition. J Clin Invest 119 (6):1420-1428

2. Heldin C-H, Landström M, Moustakas A (2009) Mechanism of TGF-[beta] signaling to growth arrest, apoptosis, and epithelialmesenchymal transition. Curr Opin Cell Biol 21(2):166-176

3. Pachernik J, Soucek K, Hampl A, Hofmanova J, Kozubik A (2001) Transforming growth factor-betal induces junB mRNA accumulation, Gl-phase arrest, and pRb dephosphorylation in human leukemia HL-60 cells. Folia Biol 47(1):32-35

4. Soucek K, Pachernik J, Kubala L, Vondracek J, Hofmanova J, Kozubik A (2006) Transforming growth factor-betal inhibits all-trans retinoic acid-induced apoptosis. Leuk Res 30 (5):607-623

5. Zeisberg M (2009) Biomarkers for epithelial-mesenchymal transitions. J Clin Invest 119(6):1429-1437

6. Xi B, Yu N, Wang X, Xu X, Abassi YA (2008) The application of cell-based label-free technology in drug discovery. Biotechnol J 3(4):484-495
7. Otto AM, Brischwein M, Grothe H, Motrescu E, Wolf B (2003) Multiparametric sensor chips for chemosensitivity testing of sensitive and resistant tumor cells. Recent Results Cancer Res 161:39-47

8. Keese CR, Bhawe K, Wegener J, Giaever I (2002) Real-time impedance assay to follow the invasive activities of metastatic cells in culture. Biotechniques 33(4):842-844, 846, 848-850

9. Spegel C, Heiskanen A, Lars Henrik, Skjolding D, Emnéus J (2008) Chip based electroanalytical systems for cell analysis. Electroanalysis 20 (6):680-702

10. Maeda M, Johnson KR, Wheelock MJ (2005) Cadherin switching: essential for behavioral but not morphological changes during an epithelium-to-mesenchyme transition. J Cell Sci 118 (5):873-887

11. Yu N, Atienza JM, Bernard J, Blanc S, Zhu J, Wang X, Xu X, Abassi YA (2006) Realtime monitoring of morphological changes in living cells by electronic cell sensor arrays: an approach to study $\mathrm{G}$ proteincoupled receptors. Anal Chem 78(1): 35-43 